\title{
Plant Growth and Leaf Antioxidant Metabolism of Four Elite Grass Pea (Lathyrus sativus) Genotypes, Differing in Arsenic Tolerance
}

\author{
Dibyendu Talukdar
}

Received: 7 July 2013/Accepted: 20 September 2013/Published online: 15 October 2013

(C) NAAS (National Academy of Agricultural Sciences) 2013

\begin{abstract}
Response of four improved grass pea (Lathyrus sativus L.) genotypes to arsenic was tested in pot experiment

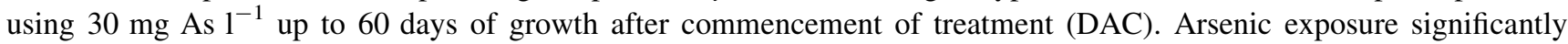
reduced growth and seed yield potential of vars B1 and BioL-212, but no such effect was observed in bold-seeded mutant and pod indehiscent mutant lines. Results revealed normal leaf photosynthesis and antioxidant metabolism at 20 DAC in both varieties. However, high superoxide dismutase activity coupled with low ascorbate redox and declining ascorbate peroxidase level led to abnormal rise in $\mathrm{H}_{2} \mathrm{O}_{2}$ content at reproductive stages (40 and 60 DAC), consequently, resulting in significantly enhanced arsenic-induced oxidative damage and physiological impediment in both varieties. By contrast, $\mathrm{H}_{2} \mathrm{O}_{2}$ level in both the mutants was remarkably modulated at reproductive stage (40 DAC) in a highly controlled manner by balanced action of antioxidant defense. This favored normal photosynthesis and ensured good grain yield even under prolonged arsenic exposure by effectively preventing oxidative damage to membrane in both the mutants. Native PAGE analysis revealed that enzyme isoforms were involved in the regulation of foliar $\mathrm{H}_{2} \mathrm{O}_{2}$ metabolism, the level of which was found extremely critical in determining arsenic tolerance of grass pea genotypes.
\end{abstract}

Keywords Arsenic - Antioxidant defense - Oxidative stress $\cdot \mathrm{H}_{2} \mathrm{O}_{2} \cdot$ Grain yield Grass pea

\section{Introduction}

Arsenic (As) is a ubiquitous toxic metalloid. In recent times, the impact of irrigation with high-arsenic-containing groundwater on soil and crop has drawn huge attention due to its transfer to the food chain via groundwater-plant-soil system $[2,12,13]$. The arsenate oxyanions $\mathrm{HAsO}_{4}{ }^{2-}$ and $\mathrm{H}_{2} \mathrm{AsO}_{4}{ }^{-}$are the most prevalent forms of arsenic in surface soil, water, and within cells, and these oxyanions contain arsenic in the pentavalent state [As (V)]. Being chemically very similar to phosphate, arsenate $[\mathrm{As}(\mathrm{V})]$ is readily taken up by high-affinity phosphate transporter in plants and $>95 \%$ of it is readily reduced to more toxic arsenite [As (III)] in planta by arsenate reductase activity $[1,50]$. While

D. Talukdar $(\bowtie)$

Department of Botany, R.P.M. College, University of Calcutta, Uttarpara, Hooghly 712258, West Bengal, India

e-mail: dibyendutalukdar9@gmail.com
As (III) is the predominant arsenic species in anaerobic (flooded paddy) soils, As (V) was prevalent in aerobic soils, and toxicity of arsenic often varies between crops depending on the nature of arsenic speciation [26, 50]. Flooding of paddy soils leads to mobilization of As (III) into the soil solution and transport of As (III) through highly efficient Si transport in rice [50]. At higher concentrations $(>100 \mu \mathrm{M})$, As (III) influx was substantially faster than As (V), and unlike As (V) uptake, As (III) uptake was inhibited by glycerol and antimonite, but not by phosphate, and may be taken up by aquaporin channels such as different subfamilies of nodulin26-like intrinsic proteins (NIPs) and other intrinsic proteins involved in As (III) permeability through membrane in plant $[7,30]$. In legume roots, the rhizobial bacteria enzymatically reduce absorbed arsenate to highly toxic arsenite and efflux the arsenite out of the cell through aquaglyceroporin channel [42]. In rice, bidirectional transport (influx and efflux) of As (III) is reportedly facilitated by silicon transporter Lsi1 
(OsNIP2;1, an aquaporin channel) [54]. However, besides its rapid efflux, As (III) is detoxified by complexation with either thiol-rich peptides such as reduced glutathione and phytochelatins (PCs) or vacuolar sequestration $[50,54]$ or a combination of both [50]. Recent study identified AtABCC1 and AtABCC2 as major vacuolar PC-arsenic transporters [39] in Arabidopsis thaliana, and the vacuolar transporter (ACR3) essential for As (III) transport and arsenic tolerance has been identified in arsenic hyperaccumulator fern, Pteris vittata [21]. Arsenate is efflux to the external medium similar to the phosphate efflux through anion channels [54].

Accumulating evidences indicates that arsenic can induce oxidative stress through excess reactive oxygen species (ROS) accumulation in major crops like cereals and legumes [15, 17, 18, 27, 35-37, 46]. As (V) exposure induces oxidative stress in rice seedlings [37], affecting amino acids, mineral nutrient status, antioxidant, phytohormone, and lipid metabolism [13, 53]. Differential response to As (III) and As (V) treatments was observed in rice transcriptomic analysis [10], during wheat seed germinations and carbohydrate metabolism [24], and in arsenic hyperaccumulator and sensitive plant species [40]. Among the legumes, arsenic reportedly perturbed photosynthetic capacity and impeded growth potential by inducing severe oxidative stress in pea, lentil, chickpea, mung beans, common beans, fenugreek and forage crops [28, 35, 36, 41, 46, 47]. To combat this stress, plants have developed well-integrated antioxidant defense systems, in which ascorbate (AsA) plays pivotal role as non-enzymatic antioxidant during scavenging of $\mathrm{H}_{2} \mathrm{O}_{2}$, a highly diffusible ROS [14]. Superoxide dismutase (SOD) constitutes the first line of defense against superoxide radicals, but it steadily generates $\mathrm{H}_{2} \mathrm{O}_{2}$ during their dismutation [3], which is readily scavenged by AsA-dependent ascorbate peroxidase (APX) and by catalases (CAT) [14]. These three prominent $\mathrm{H}_{2} \mathrm{O}_{2}$-metabolizing enzymes hold key in controlling $\mathrm{H}_{2} \mathrm{O}_{2}$ level during the onset of oxidative stress in plants [14]. Activities of all the three $\mathrm{H}_{2} \mathrm{O}_{2}$-metabolizing enzymes were decreased during the onset of arsenic-induced oxidative damage in A. thaliana [33], while their expressions were modulated in arsenic-treated root tips of Zea mays and Vicia faba [12]. Available evidence indicates differential responses of antioxidant defense between tolerant and sensitive genotypes of major cereals, legumes, tuber crops and vegetables [18, 34, 36, 46, 47].

Grass pea (Lathyrus sativus L.) is a widely cultivated hardy cool-season legume crop and is a promising source of seed protein, minerals and antioxidant compounds [44]. Preliminary reports indicated the inhibition of plant growth due to As accumulation [43]. Despite vast areas under pulse cultivation are metal/metalloid-contaminated, virtually nothing is known about growth response and intrinsic antioxidant metabolism of grass pea to arsenic exposure. In order to ascertain the possible growth response, grain yield and role of $\mathrm{H}_{2} \mathrm{O}_{2}$ metabolism in determining sensitivity to arsenic exposure, four improved grass pea genotypes were subjected to long-term arsenic treatment. Arsenic accumulation and yield parameters were studied at harvest, while leaf photosynthesis and antioxidant parameters were analyzed at three different time intervals of growth stage.

\section{Materials and Methods}

\section{Plant Materials}

Four grass pea genotypes, namely variety BioL-212 (Rattan) and B1 (Nirmal) developed through somaclonal variation and hybridization and two induced mutant lines, namely one bold-seeded mutant (BSM) and one pod indehiscent mutant (PIM), were developed through 350-Gy gamma-ray-treated progeny of grass pea var. BioR-231 were used in the present study. All the genotypes are high yielding and contain very low $(<0.2 \%)$ seed neurotoxin contents [43].

\section{Pot Experiment and Treatment Protocols}

Fresh and healthy seeds of four grass pea genotypes (B1, BioL-212, BSM and PIM) were surface-sterilized with $\mathrm{NaOCl}(0.1 \%, w / v)$ and continuously washed under running tap water followed by distilled water. Seeds were allowed to germinate in the dark in separate sets on moistened filter paper at $25{ }^{\circ} \mathrm{C}$. Germinated seedlings were immediately transferred to 12 -in. earthen pots containing a mixture of soil, vermiculite and farm yard manure (1:1:1), as described before $[43,45]$. Seedlings were thinned to one per pot and watered evenly for uniform growth until 7 days after first emergence. The pots were kept under control condition (14-h photoperiod, 28/18 $\pm 2{ }^{\circ} \mathrm{C}$, relative humidity of $70 \pm 2 \%$ and a photon flux density of $200 \mu \mathrm{mol} \mathrm{m} \mathrm{m}^{-2}$.) in a randomized block design. Treatment was commenced on 15-day-old seedlings by watering the plants with arsenic solution (sodium arsenate, MW $312.01 \mathrm{~g} / \mathrm{mol}$; technical grade, purity $98.5 \%$, SigmaAldrich, Bangalore, India) of $30 \mathrm{mg} \mathrm{l}^{-1}$ keeping a control set (distilled water instead of arsenic solution) for each genotype in four replicates treatment ${ }^{-1}$. A pilot experiment indicated significant effect of arsenic at this concentration on seed germination and early seedling growth of grass pea [43] and, thus, was selected for the present study. Control and treated plants were allowed to grow for another 60 days after commencement of treatment (DAC). Pot soil was refreshed thrice in a week to prevent the depletion of nutrients as well as arsenic in the course of the plant's 
exposure to the metalloid. Water content of the soil was maintained at $80 \%$ of water-holding capacity. At 60 DAC, shoots and roots were harvested separately and thoroughly washed with tap water, lengths were measured, and then dry weight was determined after drying shoots and roots at $70{ }^{\circ} \mathrm{C}$ for $48 \mathrm{~h}$ till constant weight. Plant growth and yield characteristics were recorded at harvest (60 DAC). Leaf biochemical characters and antioxidant metabolism were assessed in control and treated seedlings at $20 \mathrm{DAC}$ (vegetative stage), 40 DAC (flowering stage) and 60 DAC (pod-bearing stage).

\section{Measurement of Arsenic Content}

The roots and shoots were digested in a $\mathrm{HNO}_{3}-\mathrm{HClO}_{4}(3: 1$, $\mathrm{v} / \mathrm{v})$ mixture, and arsenic concentration was determined by flow injection hydride generation atomic absorption spectrophotometer (Perkin-Elmer, FIA-HAAS Analyst 400), keeping a Standard Reference Materials (SRMs) of tomato leaves (Item number 1573a, from National Institute of Standards and Technology, USA) as part of the quality assurance/quality control protocol, as described earlier [46, 47].

\section{Determination of Chlorophyll and Total Carotenoids}

Leaf chlorophyll (Chl) and carotenoid contents were determined by the method of Lichtenthaler [25]. The contents were expressed as mg chl or carotenoids $\mathrm{g}^{-1}$ fresh weight (FW). The chl stability indices (CSI \%) were measured using the formula: (Total chl content in stressed leaves/total chl content in control leaves) $\times 100$.

\section{Photosynthetic Rate}

Leaf photosynthetic rate was assayed following Coombs et al. [11] with a portable photosynthesis system (LI6400XT, LI-COR, USA).

\section{Determination of $\mathrm{H}_{2} \mathrm{O}_{2}$ Content}

Fresh tissue of $0.1 \mathrm{~g}$ was powdered with liquid nitrogen and blended with $3 \mathrm{ml}$ acetone for $30 \mathrm{~min}$ at $4{ }^{\circ} \mathrm{C}$. Then, the sample was filtered through eight layers of gauze cloth. After the addition of $0.15 \mathrm{~g}$ of active carbon, the sample was centrifuged twice at $3,000 \mathrm{~g}$ for $20 \mathrm{~min}$ at $4{ }^{\circ} \mathrm{C}$, and then $0.2 \mathrm{ml} 20 \% \mathrm{TiCl}_{4}$ in $\mathrm{HCl}$ and $0.2 \mathrm{ml}$ ammonia were added to $1 \mathrm{ml}$ of the supernatant. After reaction, the compound was centrifuged at $3,000 \mathrm{~g}$ for $10 \mathrm{~min}$, the supernatant was discarded, and the pellet was dissolved in $3 \mathrm{ml}$ of $1 \mathrm{M} \mathrm{H}_{2} \mathrm{SO}_{4} \cdot \mathrm{H}_{2} \mathrm{O}_{2}$ content was measured from the absorbance at $410 \mathrm{~nm}$ using a standard curve, following Wang et al. [51].

Estimation of Lipid Peroxidation and Electrolyte

Leakage (EL)

Lipid peroxidation rate was determined by measuring the malondialdehyde (MDA) equivalents following Hodges et al. [19] and was expressed as nmol MDA g ${ }^{-1}$ FW. EL was assayed by measuring the ions leaching from tissue into deionized water [44].

\section{Estimation of Foliar AsA}

Reduced (AsA) and oxidized ascorbate (DHA) contents were determined following Law et al. [22]. AsA redox was calculated as AsA/(AsA + DHA).

\section{Antioxidant Enzyme Assays}

Fresh leaf tissue of $250 \mathrm{mg}$ was homogenized in $1 \mathrm{ml}$ of $50 \mathrm{mM}$ K-phosphate buffer $(\mathrm{pH} 7.8)$ containing $1 \mathrm{mM}$ EDTA, $1 \mathrm{mM}$ dithiothreitol and $2 \%$ (w/v) polyvinyl pyrrolidone (PVP) using a chilled mortar and pestle kept in an ice bath. The homogenate was centrifuged at $15,000 \mathrm{~g}$ at $4{ }^{\circ} \mathrm{C}$ for $20 \mathrm{~min}$. Clear supernatant was used for enzyme assays. For measuring APX activity, the tissue was separately ground in homogenizing medium containing $2.0 \mathrm{mM}$ AsA in addition to the other ingredients. All assays were done at $25{ }^{\circ} \mathrm{C}$. Soluble protein content was determined using BSA as a standard [8].

SOD (EC 1.15.1.1) activity was determined by nitro blue tetrazolium (NBT) photochemical assay [5] and was expressed as $U$ (unit) $\mathrm{min}^{-1} \mathrm{mg}^{-1}$ protein. One unit of SOD was equal to that amount causing a $50 \%$ decrease in SOD-inhibited NBT reduction. SOD isozymes were individualized by native PAGE on $10 \%$ acrylamide gel and were localized by a photochemical method [5]. Activity staining gels were incubated for $30 \mathrm{~min}$ in $50 \mathrm{mM} \mathrm{K}$ phosphate buffer, $\mathrm{pH} 7.5$, containing $2 \mathrm{mM} \mathrm{KCN}$ or $5 \mathrm{mM}$ $\mathrm{H}_{2} \mathrm{O}_{2}$. Cu/Zn-SOD is inhibited by $\mathrm{KCN}$ and $\mathrm{H}_{2} \mathrm{O}_{2}$; Fe-SOD is inactivated by $\mathrm{H}_{2} \mathrm{O}_{2}$ but resistant to $\mathrm{KCN}$, and Mn-SOD is resistant to both inhibitors. APX (EC 1.11.1.11) activity (nmol AsA oxidized $\mathrm{min}^{-1} \mathrm{mg}^{-1}$ protein) was assayed following Nakano and Asada [31] with $\mathrm{H}_{2} \mathrm{O}_{2}$-dependent oxidation of AsA followed by a decrease in the absorbance at $290 \mathrm{~nm}\left(\varepsilon=2.8 \mathrm{mM}^{-1} \mathrm{~cm}^{-1}\right)$. Native PAGE of APX isozymes was performed in $4 \%$ gel and stained following Mittler and Zilinskas [29] based on the inhibition of NBT reduction by AsA. CAT (EC 1.11.1.6)-specific activity (nmol $\mathrm{H}_{2} \mathrm{O}_{2}$ degraded $\mathrm{min}^{-1} \mathrm{mg}^{-1}$ protein) was calculated using the molar absorptivity of $43.6 \mathrm{M}^{-1} \mathrm{~cm}^{-1}$ for $\mathrm{H}_{2} \mathrm{O}_{2}$ at 
$240 \mathrm{~nm}$ [9]. CAT isozyme profiling was done on $6 \%$ acrylamide gel, following Woodbury et al. [52].

\section{Statistical Analyses}

The results are the mean values \pm standard error (SE) of at least four replicates. Means were compared by ANOVA using the SPSS v. 10 (SPSS Inc., USA) and evaluated using Duncan's multiple range test at $P \leq 0.05$. Simple correlation was carried out among different traits using Microsoft Excel data analysis tool pack 2007, and the significance of correlation coefficient was tested (twotailed mode) using the formula: $t$ ( $t$ test) $=r \sqrt{ }(n-2) /$ $\left.\sqrt{ }\left(1-r^{2}\right)\right]$, where $r=$ the sample correlation and $n=10$, the sample size [42].

\section{Results}

Effect of Arsenic on Seedling Growth, Seed Yield and As Accumulation

Arsenic treatment $\left(30 \mathrm{mg} \mathrm{As} \mathrm{l}^{-1}\right.$ ) induced significant $(P<0.05)$ variations among four grass pea genotypes for growth and seed yield components (Table 1). Comparing control, plant height, primary branches/plant, shoot dry weight, pods/plant, 100 seed weight and seed yield/plant were decreased significantly in variety B1 and BioL-212, but were quite normal in BSM and PIM mutant lines under arsenic exposure (Table 1). Root dry weight and length, however, were nearly normal in all treated genotypes. In general, roots contained higher arsenic in comparison with shoots, but substantial amount of arsenic was also measured in shoots of all genotypes with highest content in variety B1 and the lowest one in the BSM line (Table 1).

\section{Leaf Photosynthesis}

In treated B1 and BioL-212, pigment composition, chl $a / b$ ratio, CSI $\%$ and photosynthetic rate were marginally changed at 20 and 40 DAC, respectively, but were significantly reduced thereafter (Fig. 1a-c). All the parameters, however, were significantly lower in both BSM and PIM lines at $20 \mathrm{DAC}$, but became normal at $40 \mathrm{DAC}$ and was stabilized at 60 DAC (Fig. 1a-c; Table 1). Considering all four genotypes, photosynthesis rate showed significant association with pods/plant $(r=0.82, t=4.052), 100$ seed weight $(r=0.70, t=2.772)$, seed yield/plant $(r=0.75$, $t=3.207)$ and shoot dry weight $(r=0.73, t=3.021)$ at 60 DAC.
Arsenic-induced $\mathrm{H}_{2} \mathrm{O}_{2}$ Accumulation, Lipid

Peroxidation and Electrolyte Leakage (EL\%)

Accumulation of $\mathrm{H}_{2} \mathrm{O}_{2}$, MDA and EL\% was significantly higher in B1 and BioL-212 over control at 60 DAC, but was quite normal in B1 up to $20 \mathrm{DAC}$ and in BioL-212 till 40 DAC (Fig. 1d-f). Contrastingly, arsenic treatment led to significant rise in $\mathrm{H}_{2} \mathrm{O}_{2}$ level, MDA and EL\% in BSM and PIM lines at $20 \mathrm{DAC}$, but barring $\mathrm{H}_{2} \mathrm{O}_{2}$, MDA content and EL\% became normal at 40 and 60 DAC (Fig. 1d-f).

Antioxidant Defense Responses to Arsenic Treatment

AsA content and AsA redox were significantly higher in arsenic-treated B1 at 20 DAC and BioL-212 up to 40 DAC, but was markedly reduced in both varieties at 60 DAC (Table 2). Both values were significantly lower in the mutant lines at $20 \mathrm{DAC}$, but were increased to normal level at 40 and 60 DAC (Table 2).

SOD activity was significantly higher over the control in BioL-212, BSM and PIM throughout the treatment period and in B1 at later stages of growth. APX activity was initially normal in B1 and BioL-212, but was reduced even below the control level at 60 DAC (Table 2). It was significantly low in mutant lines at 20 DAC, but was markedly enhanced over control at 60 DAC (Table 2). CAT activity was normal to high in $\mathrm{B} 1$ and both mutant lines at $60 \mathrm{DAC}$, but was significantly reduced in BioL-212 (Table 2).

Altogether, five activity bands were resolved for SOD on the basis of their increasing mobility and sensitivity to $\mathrm{H}_{2} \mathrm{O}_{2}$ and $\mathrm{KCN}$ at 60 DAC (Fig. 2a, b). Cu/Zn I and II were consistently resolved in control plants (Fig. 2a). In addition to $\mathrm{Cu} / \mathrm{Zn} \mathrm{I}$ and II, Mn-SOD I was formed in B1 and BioL212, exhibiting stronger intensity in case of latter. Mn-SOD I and II, and Mn-SOD I and Fe-SOD, additional to $\mathrm{Cu} / \mathrm{Zn}$ SOD I and II, were resolved in BSM and PIM, respectively (Fig. 2a, b). For APX, three isoforms (APX 1, APX 2 and APX 3) occurred in leaf extracts of control plants and in arsenic-treated B1 and BioL-212 at 60 DAC (Fig. 3a). Band intensity of all three isoforms was reduced considerably in B1 and BioL-212, but a new band resolved as APX 4 in addition to APX 1, APX 2 and APX 3 appeared in BSM and PIM lines (Fig. 3a). CAT activity was uniformly visualized as a single zone across the genotypes. Comparing control, band intensity was much higher in the two mutant lines, but was considerably lower in BioL-212 at 60 DAC (Fig. 3b).

\section{Discussion}

Growth inhibition is the most distinct manifestation of arsenic-induced toxicity in plants [2, 12, 17, 43]. Arsenic 
Table 1 Effect of arsenic (As) treatments $\left(30 \mathrm{mg}^{-1}\right.$ ) on plant growth, yield and As accumulation in control and four treated genotypes of $L$. sativus $\mathrm{L}$.

\begin{tabular}{|c|c|c|c|c|c|}
\hline \multirow[t]{2}{*}{ Traits } & \multirow[t]{2}{*}{ Control } & \multicolumn{4}{|c|}{ As-treated genotypes } \\
\hline & & B1 & BioL-212 & BSM & PIM \\
\hline Plant height $(\mathrm{cm})$ & $48.09 \pm 1.47 \mathrm{a}$ & $29.68 \pm 2.39 c$ & $37.12 \pm 1.52 b$ & $49.17 \pm 1.49 \mathrm{a}$ & $45.54 \pm 1.18 \mathrm{a}$ \\
\hline Primary branches/plant & $12.15 \pm 0.78 \mathrm{a}$ & $5.50 \pm 0.39 b$ & $7.90 \pm 0.51 \mathrm{c}$ & $13.65 \pm 0.81 \mathrm{a}$ & $12.95 \pm 0.89 a$ \\
\hline Root length (cm) & $16.38 \pm 2.01 \mathrm{a}$ & $16.13 \pm 1.19 \mathrm{a}$ & $17.10 \pm 1.23 \mathrm{a}$ & $17.21 \pm 1.43 \mathrm{a}$ & $16.23 \pm 1.39 \mathrm{a}$ \\
\hline Root DW (g/plant) & $0.29 \pm 0.80 \mathrm{a}$ & $0.28 \pm 0.91 \mathrm{a}$ & $0.31 \pm 0.29 \mathrm{a}$ & $0.32 \pm 0.71 b$ & $0.30 \pm 0.87 \mathrm{c}$ \\
\hline Shoot DW (g/plant) & $0.19 \pm 0.47 a$ & $0.05 \pm 0.53 b$ & $0.06 \pm 0.45 b$ & $0.22 \pm 0.49 \mathrm{a}$ & $0.20 \pm 0.33 a$ \\
\hline Pods/plant & $88.10 \pm 3.84 a$ & $14.70 \pm 4.35 c$ & $21.42 \pm 4.11 b$ & $89.86 \pm 0.39 a$ & $86.77 \pm 0.42 \mathrm{a}$ \\
\hline 100 seed weight $(\mathrm{g})$ & $5.51 \pm 1.28 b$ & $2.73 \pm 1.30 \mathrm{c}$ & $2.77 \pm 1.36 \mathrm{c}$ & $11.61 \pm 1.18 \mathrm{a}$ & $5.89 \pm 1.19 b$ \\
\hline Seed yield/plant (g) & $16.56 \pm 5.20 \mathrm{~b}$ & $6.56 \pm 0.33 d$ & $10.68 \pm 0.89 c$ & $20.02 \pm 3.46 a$ & $15.78 \pm 3.69 b$ \\
\hline \multicolumn{6}{|l|}{ As content $\left(\mathrm{mg} \mathrm{kg}^{-1} \mathrm{DW}\right)$} \\
\hline Shoots & $0.02 \pm 0.16 \mathrm{~d}$ & $0.51 \pm 0.21 \mathrm{a}$ & $0.39 \pm 0.30 \mathrm{~b}$ & $0.15 \pm 0.48 \mathrm{c}$ & $0.18 \pm 0.18 c$ \\
\hline Roots & $0.03 \pm 0.18 \mathrm{c}$ & $0.60 \pm 0.22 \mathrm{a}$ & $0.53 \pm 0.43 \mathrm{a}$ & $0.19 \pm 0.36 b$ & $0.22 \pm 0.44 b$ \\
\hline Chl $a\left(\mathrm{mg} \mathrm{g}^{-1} \mathrm{FW}\right)$ & $4.11 \pm 0.38 \mathrm{a}$ & $1.03 \pm 0.49 \mathrm{c}$ & $1.37 \pm 0.39 b$ & $4.13 \pm 0.39 \mathrm{a}$ & $4.09 \pm 0.40 \mathrm{a}$ \\
\hline Chl $b\left(\mathrm{mg} \mathrm{g}^{-1} \mathrm{FW}\right)$ & $1.79 \pm 0.37 \mathrm{a}$ & $1.81 \pm 0.42 \mathrm{a}$ & $1.75 \pm 0.37 \mathrm{a}$ & $1.77 \pm 0.39 \mathrm{a}$ & $1.71 \pm 0.40 \mathrm{a}$ \\
\hline Chl $a / b$ & $2.30 \pm 0.31 \mathrm{a}$ & $0.57 \pm 0.41 \mathrm{a}$ & $0.78 \pm 0.47 b$ & $2.33 \pm 0.33 c$ & $2.61 \pm 0.40 \mathrm{~d}$ \\
\hline CSI \% & $100.0 \pm 0.23 \mathrm{a}$ & $48.15 \pm 0.38 \mathrm{a}$ & $52.90 \pm 0.28 \mathrm{a}$ & $100.0 \pm 0.25 \mathrm{a}$ & $98.0 \pm 0.33 \mathrm{a}$ \\
\hline Carotenoids (mg g $\left.{ }^{-1} \mathrm{FW}\right)$ & $1.51 \pm 0.31 \mathrm{a}$ & $1.49 \pm 0.30 \mathrm{a}$ & $1.51 \pm 0.30 \mathrm{a}$ & $1.49 \pm 0.29 \mathrm{a}$ & $1.50 \pm 0.35 \mathrm{a}$ \\
\hline Leaf photosynthetic rate, $\mu \mathrm{M} \mathrm{CO}_{2} /\left(\mathrm{m}^{2} \mathrm{~s}\right)$ & $13.19 \pm 0.76 a$ & $6.39 \pm 0.49 d$ & $7.11 \pm 0.53 \mathrm{c}$ & $12.76 \pm 0.66 b$ & $13.45 \pm 0.81 \mathrm{a}$ \\
\hline
\end{tabular}

Data were recorded at harvest $(60 \mathrm{DAC})$ and presented as mean $\pm \mathrm{SE}$ of four replicates. Different letters in each row indicate significant differences at $P \leq 0.05$ in ANOVA followed by Duncan's multiple range test

effect at $30 \mathrm{mg} \mathrm{l}^{-1}$ on growth of 60 -day-old treated grass pea genotypes observed in the present investigation, however, is not straightforward, and significant variation was observed among four genotypes for the traits. Decreased shoot dry weight in B1 and BioL-212 under arsenic treatment might be attributed to significant reduction in plant height $(r=0.72, t=2.935)$, number of primary branches $(r=0.82, t=4.052)$, and to low pods/plant $(r=0.82$, $t=4.052)$ and 100 seed weight $(r=0.73, t=2.778)$. Significant positive correlation of photosynthesis with shoot dry weight and yield components at 60 DAC suggested serious consequences of low photosynthesis at reproductive stage on grain yield of the treated varieties. By contrast, despite the disruption of photosynthetic apparatus at initial growth period, good grain yield in the treated mutants was ensured through efficient and timely turnover of photosynthesis at reproductive stages $(40,60$ DAC) when mobilization of food materials toward sink is an important event for proper grain filling [16]. The restoration of normal photosynthesis in the two mutants despite continuous arsenic exposure has immense agronomic significance as photosynthetic pigments are some of the most important internal physiological factors, which are believed to be the targets of arsenic-induced toxicity in crop plants [35, 36, 41, 46, 47]. However, shoot/root arsenic in the present control plants (0.67) increased to 0.85 in B1, 0.74 in BioL-212, 0.79 in BSM and 0.82 in PIM, strongly indicating arsenic accumulation in shoots of treated seedlings, and agreed well with reported bioaccumulation and transport of arsenic in vegetative and edible part of major grain, spice and forage legumes $[17,35,46$, 47].

In order to understand the intrigues behind differential arsenic sensitivity of four genotypes, role of AsA and activities of three prominent $\mathrm{H}_{2} \mathrm{O}_{2}$-metabolizing enzymes were assayed. These four components play vital roles in primary defense mechanism of plants during ROS detoxification particularly $\mathrm{H}_{2} \mathrm{O}_{2}$ [4, 14]. The dual roles of $\mathrm{H}_{2} \mathrm{O}_{2}$ as a stress inducer and as a signaling molecule to upregulate antioxidant defense against oxidative damage have been increasingly recognized [20, 32, 45]. In the present study, a time-bound measurement at 20,40 and 60 DAC revealed a completely reverse situation between varieties and mutant lines for $\mathrm{H}_{2} \mathrm{O}_{2}$ level. High SOD activity strongly suggested arsenic-induced generation of excess superoxide radicals, and subsequently, their dismutation formed huge $\mathrm{H}_{2} \mathrm{O}_{2}$ in treated seedlings. Results indicated that the normal level of leaf $\mathrm{H}_{2} \mathrm{O}_{2}$ in the treated varieties was maintained by opposite mechanisms of SOD and APX, balancing it to a particular level during initial treatment period. Despite normal CAT activity, this critical balance, however, was lost when APX activity began to decline in both the varieties at reproductive period due to prolonged arsenic exposure. Same situation was experienced by 
Fig. 1 Changes in

a chlorophyll $a$ content,

b chlorophyll stability index

(CSI \%), c photosynthetic rate,

d accumulation of $\mathrm{H}_{2} \mathrm{O}_{2}$,

e malondialdehyde content and

f electrolyte leakage \% in leaves

of variety B1 and BioL-212 and

BSM-bold-seeded mutant and

PIM-pod indehiscent mutant

of grass pea at 20,40 and

60 days after commencement

(DAC) of arsenic treatment (0)

with sodium arsenate at

$30 \mathrm{mg} \mathrm{l}^{-1}$. Data presented here are mean $\pm \mathrm{SE}$ of four

replicates. Means with different small letters are significantly different at $P \leq 0.05$ by

ANOVA followed by Duncan's multiple range test
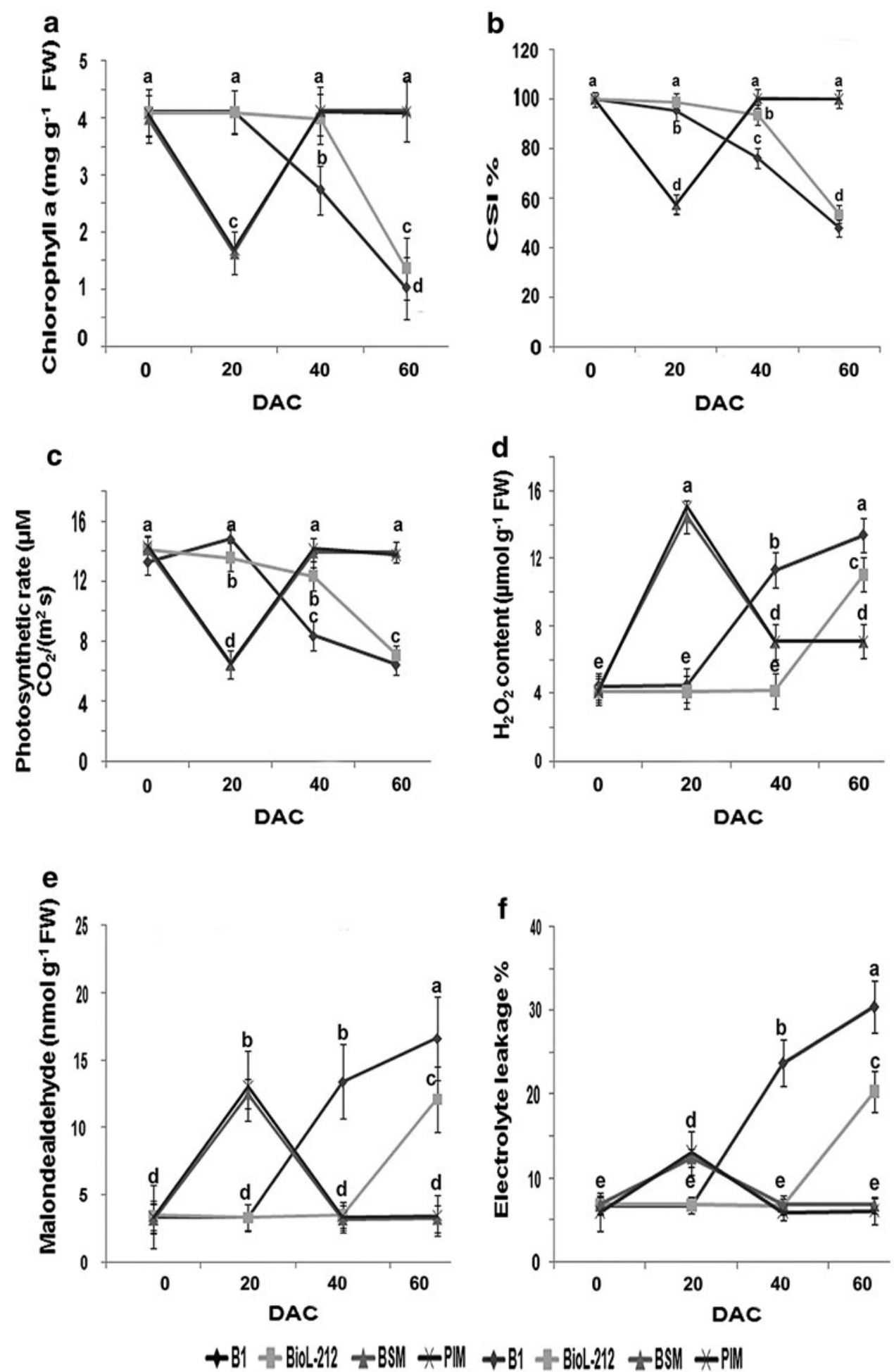

arsenic-treated mutant lines but only at 20 DAC. Increasing SOD activity continuously generated $\mathrm{H}_{2} \mathrm{O}_{2}$, which could not be counterbalanced by abrupt decrease in APX and CAT. Declining level of APX might be due to nearly twofold decrease in AsA level and its redox state in B1 and BioL-212. Besides serving as co-factor of APX, AsA itself can detoxify ROS through non-enzymatic mechanism [38, $44]$ and its availability and redox state plays key roles in signaling network through controlled metabolism of $\mathrm{H}_{2} \mathrm{O}_{2}$ during metal stress [6]. $\mathrm{H}_{2} \mathrm{O}_{2}$ has a longer half-life than superoxides [4, 14, 20], and therefore, its initial surge in leaves of arsenic-treated mutants indicated early "oxidative 
Table 2 Effect of arsenic (As) treatments $\left(30 \mathrm{mg} \mathrm{l}^{-1}\right)$ on reduced (AsA), redox state of ascorbate and activities of superoxide dismutase (SOD, $\mathrm{U} \mathrm{min}{ }^{-1} \mathrm{mg}^{-1}$ protein), ascorbate peroxidase (APX, nmol AsA oxidized $\min ^{-1} \mathrm{mg}^{-1}$ protein) and catalases (CAT, nmol $\mathrm{H}_{2} \mathrm{O}_{2}$ degraded $\mathrm{min}^{-1} \mathrm{mg}^{-1}$ protein) in leaves of control and four treated genotypes at control (0) and 20, 40 and 60 days after commencement of treatment (DAC) of L. sativus L.

\begin{tabular}{|c|c|c|c|c|c|}
\hline Parameters & DAC & B1 & BioL-212 & BSM & PIM \\
\hline \multirow[t]{4}{*}{ AsA $\left(\mu \mathrm{mol} \mathrm{g}{ }^{-1} \mathrm{FW}\right)$} & 0 & $1.81 \pm 10.4 \mathrm{ab}^{\prime}$ & $1.75 \pm 10.6 b^{\prime}$ & $1.89 \pm 12.4 \mathrm{aa}^{\prime}$ & $1.69 \pm 11.7 \mathrm{ba}^{\prime}$ \\
\hline & 20 & $3.39 \pm 14.8 \mathrm{aa}^{\prime}$ & $2.98 \pm 10.3 \mathrm{aa}^{\prime}$ & $1.18 \pm 17.3 b^{\prime}$ & $1.07 \pm 7.8 \mathrm{bb}^{\prime}$ \\
\hline & 40 & $1.10 \pm 7.3 \mathrm{cc}^{\prime}$ & $3.12 \pm 13.0 \mathrm{aa}^{\prime}$ & $1.76 \pm 8.8 \mathrm{ba}^{\prime}$ & $1.65 \pm 7.2 \mathrm{ba}^{\prime}$ \\
\hline & 60 & $0.91 \pm 7.9 \mathrm{~cd}^{\prime}$ & $0.98 \pm 10.0 \mathrm{cc}^{\prime}$ & $1.83 \pm 7.9 \mathrm{aa}^{\prime}$ & $1.71 \pm 8.1 \mathrm{ba}^{\prime}$ \\
\hline \multirow[t]{4}{*}{ AsA redox $[\mathrm{AsA} /(\mathrm{AsA}+\mathrm{DHA})]$} & 0 & $0.856 \pm 0.09 \mathrm{a} \mathrm{a}^{\prime}$ & $0.891 \pm 0.09 \mathrm{aa}^{\prime}$ & $0.910 \pm 0.08 \mathrm{aa}^{\prime}$ & $0.913 \pm 0.10 \mathrm{aa}^{\prime}$ \\
\hline & 20 & $0.932 \pm 0.11 \mathrm{aa}^{\prime}$ & $0.943 \pm 0.10 \mathrm{aa}^{\prime}$ & $0.657 \pm 0.12 b^{\prime}$ & $0.639 \pm 0.09 b^{\prime}$ \\
\hline & 40 & $0.542 \pm 0.08 \mathrm{bb}^{\prime}$ & $0.951 \pm 0.09 \mathrm{aa}^{\prime}$ & $0.868 \pm 0.09 \mathrm{aa}^{\prime}$ & $0.890 \pm 0.11 \mathrm{aa}^{\prime}$ \\
\hline & 60 & $0.461 \pm 0.09 b c^{\prime}$ & $0.458 \pm 0.11 b^{\prime}$ & $0.905 \pm 0.09 \mathrm{aa}^{\prime}$ & $0.915 \pm 0.12 \mathrm{aa}^{\prime}$ \\
\hline \multirow[t]{4}{*}{ SOD } & 0 & $111.5 \pm 5.1 \mathrm{ac}^{\prime}$ & $118.9 \pm 4.9 \mathrm{ac}^{\prime}$ & $113.3 \pm 4.7 \mathrm{ab}^{\prime}$ & $111.5 \pm 5.5 \mathrm{a} \mathrm{b}^{\prime}$ \\
\hline & 20 & $110.9 \pm 5.8 \mathrm{cc}^{\prime}$ & $169.8 \pm 4.8 \mathrm{bb}^{\prime}$ & $189.7 \pm 5.1 \mathrm{aa}^{\prime}$ & $191.6 \pm 7.7 \mathrm{aa}^{\prime}$ \\
\hline & 40 & $148.8 \pm 4.8 b^{\prime}$ & $191.8 \pm 10.5 \mathrm{aa}^{\prime}$ & $193.6 \pm 9.8 \mathrm{aa}^{\prime}$ & $189.8 \pm 8.5 \mathrm{aa}^{\prime}$ \\
\hline & 60 & $205.6 \pm 11.6 a^{\prime}$ & $190.6 \pm 9.8 \mathrm{aa}^{\prime}$ & $195.1 \pm 6.9 \mathrm{aa}^{\prime}$ & $197.5 \pm 10.2 \mathrm{aa}^{\prime}$ \\
\hline \multirow[t]{4}{*}{ APX } & 0 & $175.8 \pm 7.8 \mathrm{ba}^{\prime}$ & $169.9 \pm 8.1 b^{\prime}$ & $180.5 \pm 8.9 \mathrm{ac}^{\prime}$ & $181.7 \pm 10.0 \mathrm{ac}^{\prime}$ \\
\hline & 20 & $174.7 \pm 8.6 \mathrm{ba}^{\prime}$ & $337.7 \pm 12.6 \mathrm{aa}^{\prime}$ & $60.3 \pm 4.3 \mathrm{~cd}^{\prime}$ & $51.73 \pm 4.5 \mathrm{dd}^{\prime}$ \\
\hline & 40 & $77.9 \pm 4.9 \mathrm{cb}^{\prime}$ & $329.6 \pm 9.3 \mathrm{ba}^{\prime}$ & $450.4 \pm 18.5 \mathrm{aa}^{\prime}$ & $458.8 \pm 13.2 \mathrm{aa}^{\prime}$ \\
\hline & 60 & $58.7 \pm 6.1 \mathrm{cc}^{\prime}$ & $109.3 \pm 5.5 \mathrm{bc}^{\prime}$ & $324.5 \pm 11.3 \mathrm{ab}^{\prime}$ & $327.1 \pm 10.9 \mathrm{ab}^{\prime}$ \\
\hline \multirow[t]{4}{*}{ CAT } & 0 & $39.1 \pm 4.7 \mathrm{aa}^{\prime}$ & $40.1 \pm 6.7 \mathrm{aa}^{\prime}$ & $37.7 \pm 5.1 \mathrm{ab}^{\prime}$ & $39.8 \pm 5.6 \mathrm{ab}^{\prime}$ \\
\hline & 20 & $40.5 \pm 3.8 \mathrm{aa}^{\prime}$ & $38.8 \pm 6.4 \mathrm{aa}^{\prime}$ & $21.6 \pm 4.9 b c^{\prime}$ & $19.9 \pm 5.7 b c^{\prime}$ \\
\hline & 40 & $40.1 \pm 4.1 \mathrm{ba}^{\prime}$ & $40.3 \pm 4.7 \mathrm{ba}^{\prime}$ & $51.5 \pm 5.3 \mathrm{aa}^{\prime}$ & $53.7 \pm 6.0 \mathrm{aa}^{\prime}$ \\
\hline & 60 & $36.7 \pm 5.0 \mathrm{ba}^{\prime}$ & $18.9 \pm 5.1 \mathrm{cb}^{\prime}$ & $58.6 \pm 6.1 \mathrm{aa}^{\prime}$ & $57.7 \pm 5.9 \mathrm{aa}^{\prime}$ \\
\hline
\end{tabular}

Data were presented as mean \pm SE of four replicates. Different small letters in each row indicate significant differences among genotypes, and letters with prime in each column indicate significant differences among treatments (for a particular trait) at $P \leq 0.05$ by ANOVA followed by Duncan's multiple range test

burst" in the photosynthetic organs, which might trigger enhanced defense response against excess ROS at the later stages of growth. Rise in APX activity powered by high AsA redox and increasing CAT level at $40 \mathrm{DAC}$ and at 60 DAC was the strong evidence of this enhanced response. This might be instrumental to maintain $\mathrm{H}_{2} \mathrm{O}_{2}$ in mutants at a particular level, which is still significantly higher than control but was considerably lower than that of both varieties and was not toxic to normal reproductive growth of treated mutants, as was also observed in cadmium-treated lentil seedlings [45] and during arsenic-induced induction of Fusarium wilting in grass pea genotypes [48]. Certainly, the status of cellular $\mathrm{H}_{2} \mathrm{O}_{2}$ informed the plant cell about the severity of the oxidative stress and hence the appropriate level of antioxidant enzyme activities through induction $[20,32,48]$. Present results indicate criticality of $\mathrm{H}_{2} \mathrm{O}_{2}$ level in stress perception, which was regulated/adjusted by tolerant genotypes in favor of their growth and yield performances during prolonged exposure to arsenic. This was strongly suggested by the absence of oxidative stress symptom (normal MDA and EL\%) in shoots of both BSM and PIM lines despite the high $\mathrm{H}_{2} \mathrm{O}_{2}$ content at 60 DAC. Huge enhancement in MDA content and EL\% along with extremely high $\mathrm{H}_{2} \mathrm{O}_{2}$ content in leaves of both the varieties at this stage resulted in onset of arsenic-induced oxidative stress, which jeopardized growth and yield potential of both varieties, similar to reports in different other crop plants under arsenic exposure $[12,15,17,18,34-37,46$, 47].

Changes in antioxidant enzyme activities coincided with a variable increase or decrease in their individual isoform expressions. The intensity of enzyme bands color can reflect relative quantity of the isozyme activity. Analysis of isoform and inhibitor studies revealed that the significant enhancement in SOD activity was mainly due to appearance of Mn-SOD I isoform in B1 and BioL-212, Mn-SOD I and II isoforms in BSM and Mn-SOD I, and one Fe-SOD isoforms in PIM line. The supply of arsenic reportedly enhanced the activity of $\mathrm{Cu} / \mathrm{Zn}-\mathrm{SOD}$ II in Trifolium pratense, although no new isoforms was detected [28]. In Arabidopsis, transcripts for genes encoding a chloroplastic and a cytosolic $\mathrm{Cu} / \mathrm{Zn}-\mathrm{SOD}$ were induced by As (V) exposure, while transcripts for a Fe-SOD were downregulated [1]. Origin of three novel isoforms in the present study indicated the involvement of SOD expressions in different cellular compartments to combat the elevated 


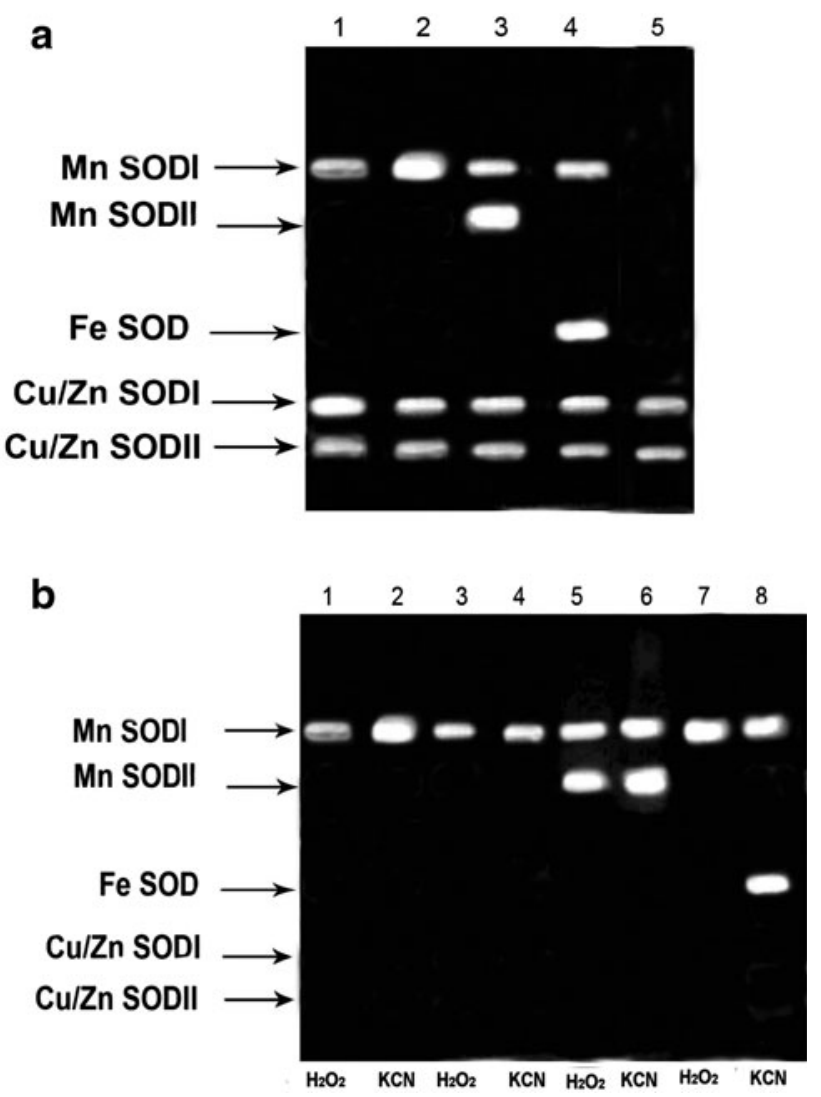

Fig. 2 a Activity gel of superoxide dismutase (SOD) in native PAGE on $10 \%$ acrylamide gels of leaf extracts of four grass pea genotypes at 60 days after commencement of arsenic (sodium arsenate $30 \mathrm{mg} \mathrm{As}^{-1}$ ) treatment; lane 1 variety $\mathrm{B} 1$, lane 2 variety BioL212 , lane 3 bold-seeded mutant, lane 4 pod indehiscent mutant and lane 5 control plants, and b inhibitor studies with $\mathrm{H}_{2} \mathrm{O}_{2}$ and $\mathrm{KCN}$ and visualization of SOD isoforms in native PAGE of leaf extracts of grass pea (L. sativus L.) variety B1 (lanes 1 and 2), variety BioL-212 (lanes 3 and 4), bold-seeded mutant (lanes 5 and 6 ) and pod indehiscent mutant (lanes 7 and 8 ) at 60 days after commencement of treatment. The control plants containing only $\mathrm{Cu} / \mathrm{Zn}-\mathrm{SOD}$ I and II showed no bands in inhibitor study, and thus not presented

generation of superoxide radicals due to arsenic exposure and suggested that grass pea lines are quite able to protect their important organelles, such as mitochondria and peroxisomes, against the detrimental effects of ROS. Interestingly enough, a recent study demonstrated that arsenic exposure significantly upregulated $\mathrm{Cu} / \mathrm{Zn}$-SODs, Fe-SODs and Mn-SODs activities in Phaseolus vulgaris genotype VL-63 but strictly regulated SOD activity in its two arsenic-tolerant SOD-deficient mutant lines by upregulating $\mathrm{Cu} / \mathrm{Zn}$-SODs expression on the one hand and downregulating Mn-SOD and Fe-SOD on the other hand [49]. For APX, the changes in activity were mainly due to enhanced/reduced expression of APX 1, APX 2 and APX 3 isozymes. The visualization of APX 4 as a unique isoform in BSM and PIM lines indicated intrinsic modulation of major $\mathrm{H}_{2} \mathrm{O}_{2}$-scavenging enzyme in the photosynthetic

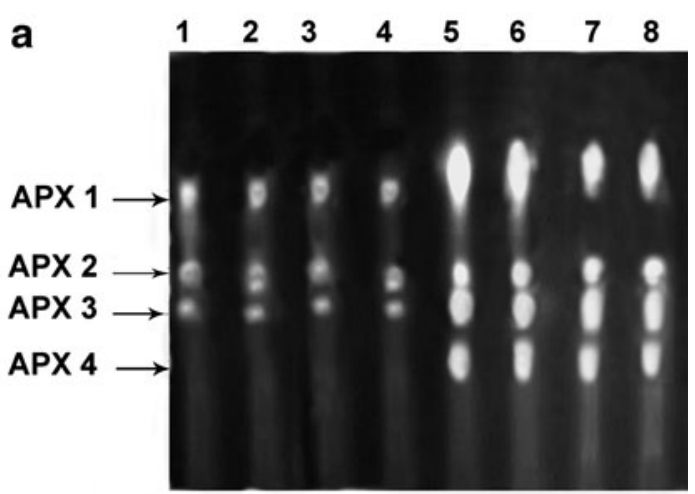

b

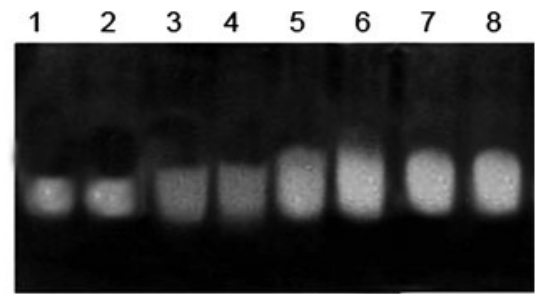

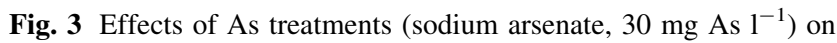
isozymes banding of a APX activity in native PAGE on $4 \%$ acrylamide gels of leaf extracts of grass pea genotypes at 60 days after commencement of treatment; lane 1 control plant, lane 2 variety B1, lanes 3 and 4 variety BioL-212, lanes 5 and 6 bold-seeded mutant and lanes 7 and 8 pod indehiscent mutant, and b CAT activity in native PAGE on $6 \%$ acrylamide gels of leaf extracts of grass pea genotypes at 60 days after commencement of treatment; lane 1 control plants, lane 2 variety B1, lanes 3 and 4 variety BioL-212, lanes 5 and 6 bold-seeded mutant, and lanes 7 and 8 pod indehiscent mutant

organ of the mutant plants. Upregulation of SODs and APX isoforms was also reported in rice seedlings, which was more pronounced in As (III) treatment compared to As (V) [37]. By contrast, transgenic tall fescue plants expressing the $\mathrm{Cu} / \mathrm{Zn}-\mathrm{SOD}$ and APX genes in chloroplasts exhibited downregulation of enzyme isoforms upon submission to arsenic treatment [23]. In wheat seedlings, arsenic induced the expression of CAT isozymes but inhibited the expression of SOD and APX isozymes at concentrations lower than $1 \mathrm{mg} \mathrm{kg}^{-1}$, while opposite result was obtained at high concentrations [24]. In the present study, increasing staining intensity confirmed the enhanced level of CAT expression in the treated mutants, while decreasing activity was manifested by declining band intensity in BioL-212 after prolonged arsenic exposure. Obviously, increased isozyme activity and/or appearance of novel isoforms in APX and CAT conferred both the mutants' appreciable capability of $\mathrm{H}_{2} \mathrm{O}_{2}$ scavenging to counterbalance enhanced SOD-generated $\mathrm{H}_{2} \mathrm{O}_{2}$ production during arsenic treatment. The variations in the isozyme pattern and their correspondence to total assayed activity suggested that the three $\mathrm{H}_{2} \mathrm{O}_{2}$-metabolizing enzymes 
responded strongly to arsenic-induced oxidative stress in grass pea genotypes.

\section{Conclusion}

Results revealed significant genotypic differences in response to $30 \mathrm{mg} \mathrm{As} 1^{-1}$ treatment and even differences between growth stages. Arsenic treatment inhibited growth and yield potential of variety B1 and BioL-212, while no such effect was observed in BSM and PIM lines. Present results also revealed the importance of reproductive stage in maintaining normal growth, photosynthesis and seed yield during prolonged arsenic exposure by mitigating oxidative damage through the modulation of $\mathrm{H}_{2} \mathrm{O}_{2}$ metabolism in fine tune. Isozyme analysis revealed origin of unique isoforms of SOD and APX in response to arsenic treatment and increase in activity of existing isoforms of SOD, APX and CAT, conferring enhanced activity.

Acknowledgments Financial assistance in the form of research project (Grant No. PSW-047/11-12 ERO) by University Grants Commission, Calcutta, India, is gratefully acknowledged.

Conflict of interest None.

\section{References}

1. Abercrombie JM, Halfhill MD, Ranjan P, Rao MR, Saxton AM, Yuan JS, Stewart CN Jr (2008) Transcriptional responses of Arabidopsis thaliana plants to As (V) stress. BMC Plant Biol 8:87

2. Ahmed FRS, Killham K, Alexander I (2006) Influences of arbuscular mycorrhizal fungus Glomus mosseae on growth and nutrition of lentil irrigated with arsenic contaminated water. Plant Soil 283:33-41

3. Alscher RG, Erturk N, Heath LS (2002) Role of superoxide dismutases (SODs) in controlling oxidative stress in plants. J Exp Bot 53:1331-1341

4. Asada K (2006) Production and scavenging of reactive oxygen species in chloroplasts and their functions. Plant Physiol 141:391-396

5. Beyer WF, Fridovich I (1987) Assaying for superoxide dismutase activity: some large consequences of minor changes in condition. Anal Biochem 161:559-566

6. Bielen A, Remans T, Vangronsveld J, Cuypers A (2013) The influence of metal stress on the availability and redox state of ascorbate, and possible interference with its cellular functions. Int J Mol Sci 14:6383-6413

7. Bienert GP, Thorsen M, Schüssler MD, Nilsson HR, Wagner A, Tamás MJ, Jahn TP (2008) A subgroup of plant aquaporins facilitate the bidirectional diffusion of $\mathrm{As}(\mathrm{OH})_{3}$ and $\mathrm{Sb}(\mathrm{OH})_{3}$ across membranes. BMC Biol 6:26

8. Bradford MM (1976) A rapid and sensitive method for the quantitation of microgram quantities of protein utilizing the principle of protein-dye binding. Anal Biochem 72:248-254

9. Chance B, Maehly AC (1955) Assay of catalases and peroxidases. Methods Enzymol 2:764-817
10. Chakrabarty D, Trivedi PK, Misra P, Tiwari M, Shri M, Shukla D, Kumar S, Rai A, Pandey A, Nigam D, Tripathi RD, Tuli R (2009) Comparative transcriptome analysis of arsenate and arsenite stresses in rice seedlings. Chemosphere 74:688-702

11. Coombs J, Hall DO, Long SP, Scurlock JMO (1985) Techniques in bioproductivity and photosynthesis. Pergamon Press, Oxford

12. Duquesnoy I, Champeau GM, Evray G, Ledoigt G, Piquet-Pissaloux A (2010) Enzymatic adaptations to arsenic-induced oxidative stress in Zea mays and genotoxic effect of arsenic in root tips of Vicia faba and Zea mays. CR Biol 333:814-824

13. Dwivedi S, Tripathi RD, Tripathi P, Kumar A, Dave R, Mishra S, Singh R, Sharma D, Rai UN, Chakrabarty D, Trivedi PK, Adhikari B, Bag MK, Dhankher OP, Tuli R (2010) Arsenate exposure affects amino acids, mineral nutrient status and antioxidants in rice (Oryza sativa L.) genotypes. Environ Sci Technol 44: 9542-9549

14. Foyer $\mathrm{CH}$, Noctor G (2003) Redox sensing and signalling associated with reactive oxygen in chloroplasts, peroxisomes and mitochondria. Physiol Plant 119:355-364

15. Gunes A, Pilbeam D, Inal A (2009) Effect of arsenic-phosphorus interaction on arsenic-induced oxidative stress in chickpea plants. Plant Soil 314:211-220

16. Gulmezoglu N, Kayan N (2011) Dry matter and nitrogen accumulation during vegetative and grain filling of lentil (Lens culinaris Medic.) as affected by nitrogen rates. Not Bot Horti Agrobot 39:196-202

17. Gupta DK, Tripathi RD, Mishra S, Srivastava S, Dwivedi S, Rai UN, Yang XE, Huanj H, Inouhe M (2008) Arsenic accumulation in root and shoot vis-a-vis its effects on growth and level of phytochelatins in seedlings of Cicer arietinum L. J Environ Biol 29:281-286

18. Hasanuzzaman M, Fujita M (2013) Exogenous sodium nitroprusside alleviates arsenic-induced oxidative stress in wheat (Triticum aestivum L.) seedlings by enhancing antioxidant defense and glyoxalase system. Ecotoxicology 22:584-596

19. Hodges DM, Delong JM, Forney CF, Prange RK (1999) Improving the thiobarbituric acid-reactive substances assay for estimating lipid peroxidation in plant tissues containing anthocyanin and other interfering compounds. Planta 207:604-611

20. Hung S-H, Yu C-W, Lin C-H (2005) Hydrogen peroxide functions as a stress signal in plants. Bot Bull Acad Sin 46:1-10

21. Indriolo E, Na G, Ellis D, Salt DE, Banksb JA (2010) A vacuolar arsenite transporter necessary for arsenic tolerance in the arsenic hyperaccumulating fern Pteris vittata is missing in flowering plants. Plant Cell 22:2045-2057

22. Law MY, Charles SA, Halliwell B (1983) Glutathione and ascorbic acid in spinach (Spinacia oleracea) chloroplast. The effect of hydrogen peroxide and paraquat. Biochem J 10:899-903

23. Lee SH, Ahsan N, Lee KW, Kim DH, Lee DG, Kwak SS, Kwon SY, Kim TH, Lee BH (2007) Simultaneous overexpression of both $\mathrm{CuZn}$ superoxide dismutase and ascorbate peroxidase in transgenic tall fescue plants confers increased tolerance to a wide range of abiotic stresses. J Plant Physiol 164:1626-1638

24. Li CX, Feng SL, Shao Y, Jiang LN, Lu XY, Hou XL (2007) Effects of arsenic on seed germination and physiological activities of wheat seedlings. J Environ Sci (China) 19:725-732

25. Lichtenthaler HK (1987) Chlorophylls and carotenoids: pigments of photosynthetic biomembranes. Methods Enzymol 148: 350-382

26. Liu X, Zhang S, Shan X, Zhu YG (2005) Toxicity of arsenate and arsenite on germination seedling growth and amylolytic activity of wheat. Chemosphere 61:293-301

27. Ma JF, Yamaji N, Mitani N, Xu X-Y, Su Y-H, McGrath SP, Zhao F-J (2008) Transporters of arsenite in rice and their role in arsenic accumulation in rice grain. Proc Natl Acad Sci USA 105:9931-9935 
28. Mascher R, Lippmann B, Holzinger S, Bergmann H (2002) Arsenate toxicity: Effects on oxidative stress response molecules and enzymes in red clover plants. Plant Sci 163:961-969

29. Mittler R, Zilinskas BA (1993) Detection of ascorbate peroxidase activity in native gels by inhibition of the ascorbate dependent reduction of nitroblue tetrazolium. Anal Biochem 212:540-546

30. Mosa KA, Kumar K, Chhikara S, McDermott J, Liu Z, Musante C, White JC, Dhankher OP (2012) Members of rice plasma membrane intrinsic proteins subfamily are involved in arsenite permeability and tolerance in plants. Transgenic Res 21(6): 1265-1277

31. Nakano Y, Asada K (1981) Hydrogen peroxide is scavenged by ascorbate-specific peroxidase in spinach chloroplasts. Plant Cell Physiol 22:867-880

32. Neill S, Desikan R, Hancock J (2002) Hydrogen peroxide signaling. Curr Opin Plant Biol 5:388-395

33. Odjegba VJ (2012) Exogenous salicylic acid alleviates arsenic toxicity in Arabidopsis thaliana. Indian J Innov Dev 1:515-522

34. Patel MJ, Parmar P, Dave B, Subramanian RB (2012) Antioxidative and physiological studies on Colocasia esculentum in response to arsenic stress. Afr J Biotechnol 11:16241-16246

35. Singh HP, Batish DR, Kohli RK, Arora K (2007) Arsenicinduced root growth inhibition in mung bean (Phaseolus aureus Roxb.) is due to oxidative stress resulting from enhanced lipid peroxidation. Plant Growth Regul 53:65-73

36. Sharma I (2013) Arsenic-induced oxidative stress and antioxidant defense system of Pisum sativum and Pennisetum typhoides: a comparative study. Res J Biotechnol 8:48-56

37. Shri M, Kumar S, Chakrabarty D, Trivedi PK, Mallick S, Misra P, Shukla D, Mishra S, Srivastava S, Tripathi RD, Tuli R (2009) Effect of arsenic on growth, oxidative stress, and antioxidant system in rice seedlings. Ecotoxicol Environ Saf 72:1102-1110

38. Smirnoff N (2000) Ascorbic acid: metabolism and functions of a multi-facetted molecule. Curr Opin Plant Biol 3:229-235

39. Song WY, Parka J, Mendoza-Cózatl DG, Suter-Grotemeyer M, Shim D, Hörtensteiner S, Geisler M, Weder B, Rea PA, Rentsch D, Schroeder JI, Lee Y, Martinoia E (2010) Arsenic tolerance in Arabidopsis is mediated by two ABCC-type phytochelatin transporters. Proc Natl Acad Sci USA 107:21187-21192

40. Srivastava S, Mishra S, Tripathi RD, Dwivedi S, Trivedi PK, Tandon PK (2007) Phytochelatins and antioxidant systems respond differentially during arsenite and arsenate stress in Hydrilla verticillata (L.f.) Royle. Environ Sci Technol 41:2930-2936

41. Stoeva N, Berova M, Zlatev Z (2005) Effect of arsenic on some physiological parameters in bean plants. Biol Plant 9:293-296

42. Takahashi Y, Minamikawa R, Hattori KH, Kurishima K, Kihou N, Yuita K (2004) Arsenic behavior in paddy fields during the cycle of flooded and non-flooded periods. Environ Sci Technol 38:1038-1044

43. Talukdar D (2011) Effect of arsenic-induced toxicity on morphological traits of Trigonella foenum-graecum L. and Lathyrus sativus L. during germination and early seedling growth. Curr Res J Biol Sci 3(2):116-123

44. Talukdar D (2012) Ascorbate deficient semi-dwarf asfL1 mutant of Lathyrus sativus exhibits alterations in antioxidant defense. Biol Plant 56(4):675-682

45. Talukdar D (2012) Exogenous calcium alleviates the impact of cadmium-induced oxidative stress in Lens culinaris Medic. seedlings through modulation of antioxidant enzyme activities. J Crop Sci Biotechnol 15(4):325-334

46. Talukdar D (2013) Arsenic-induced oxidative stress in the common bean legume, Phaseolus vulgaris L. seedlings and its amelioration by exogenous nitric oxide. Physiol Mol Biol Plants 19(1):69-79

47. Talukdar D (2013) Arsenic-induced changes in growth and antioxidant metabolism of fenugreek. Russ J Plant Physiol 60(5):652-660

48. Talukdar D (2013) Arsenic exposure modifies Fusarium wilt tolerance in grass pea (Lathyrus sativus L.) genotypes through modulation of antioxidant defense response. J Plant Sci Mol Breed 2(4):12. doi:10.7243/2050-2389-2-4

49. Talukdar D, Talukdar T (2013) Superoxide-dismutase deficient mutants in common beans (Phaseolus vulgaris L.): genetic control, differential expressions of isozymes, and sensitivity to arsenic. BioMed Res Int 2013. doi:10.1155/2013/782450

50. Tripathi RD, Tripathi P, Dwivedi S, Dubey S, Chatterjee S, Chakrabarty D, Trivedi PK (2012) Arsenomics: omics of arsenic metabolism in plants. Front Physio 3:275

51. Wang CQ, Chen M, Wang BS (2007) Betacyanin accumulation in the leaves of $\mathrm{C}_{3}$ halophyte Suaeda salsa $\mathrm{L}$. is induced by watering roots with $\mathrm{H}_{2} \mathrm{O}_{2}$. Plant Sci 172:1-7

52. Woodbury W, Spencer AK, Stahmann MA (1971) An improved procedure using ferricyanide for detecting catalase isozymes. Anal Biochem 44:301-305

53. Yu LJ, Luo YF, Liao B, Xie LJ, Chen L, Xiao S, Li JT, Hu SN, Shu WS (2012) Comparative transcriptome analysis of transporters, phytohormone and lipid metabolism pathways in response to arsenic stress in rice (Oryza sativa). New Phytol 195:97-112

54. Zhao FJ, Ago Y, Mitani N, Li RY, Su YH, Yamaji N, McGrath SP, Ma JF (2010) The role of the rice aquaporin Lsi1 in arsenite efflux from roots. New Phytol 186:392-399 